\title{
Case report and literature review: patient with gastroduodenal intussusception due to the gastrointestinal stromal tumor of the lesser curvature of the gastric body
}

\author{
Mihajlo Đokić ${ }^{1}$, Jerica Novak ${ }^{2^{*}}$ (D, Miha Petrič ${ }^{1}$, Branislava Ranković ${ }^{3}$, Miha Štabuc ${ }^{4}$ and Blaž Trotovšek
}

\begin{abstract}
Background: Intussusception in adult patient is rare. Gastroduodenal intussusception due to the gastrointestinal stromal tumors is infrequently described in the literature. Authors present a case of gastroduodenal intussusception due to the low-risk gastrointestinal stromal tumor of the lesser curvature of the gastric body with literature review.

Case presentation: Sixty-two-year-old male was admitted to our hospital with symptoms of acute gastric outlet obstruction. Imaging studies confirmed a lesion of the gastric wall producing gastroduodenal intussusception with pylorus obstruction. Upon laparotomy a tumor mass of the lesser curvature of the gastric body that invaginated through the pylorus into the duodenum was found. Desinvagination and resection of the tumor with the adequate resection margins were performed. Histology reveled a low-risk gastrointestinal stromal tumor. Due to favorable outcome only observation was suggested by the multidisciplinary team.

Conclusions: Gastroduodenal intussusception due to the gastrointestinal stromal tumor of the gastric wall is a rare event. Surgical resection is the treatment of choice. In selected cases laparosopic resection of the tumor can be performed.
\end{abstract}

Keywords: Gastroduodenal intussusception, Gastric gastrointestinal stromal tumor, Gastric outlet obstruction

\section{Background}

Intussusception rarely occurs among the adult patients. It accounts for $5 \%$ of all intussusception cases and in only $1 \%$ causes intestinal obstruction [1]. Gastroduodenal intussusception is the most infrequent form of intussusception in adults, it occurs in less than 10\% [2]. Clinical and radiological findings in a patient with gastric outlet obstruction, gastroduodenal intussusception and gastrointestinal stromal tumor (GIST) of the lesser curvature of the gastric body is presented.

\section{Case presentation}

62-year-old Caucasian male presented to the emergency room with acutely worsening epigastric pain lasting for

\footnotetext{
* Correspondence: jenovak@onko-i.si

${ }^{2}$ Department of Surgical Oncology, Ljubljana Institute of OncologyActa Chir Belg, Zaloška cesta 2, 1000 Ljubljana, Slovenia

Full list of author information is available at the end of the article
}

several days and black stool lasting for a week. Symptoms of vomiting, inappetence and weight loss that have been lasting for the past six months without doctor appointment was also reported in medical history. Patient had a history of diabetes mellitus on insulin therapy. Upon clinical examination abdomen was not distended, there was no signs of guarding or rebound tenderness. Laboratory data showed anemia (hemoglobin $119 \mathrm{~g} / \mathrm{L}$, normal range $130-170 \mathrm{~g} / \mathrm{L}$; hematocrit 0.343 , normal range $0.4-0.5)$, leukocytosis $\left(13.510^{9} / \mathrm{L}\right.$, normal range 4.0-10.0) and normal value of $\mathrm{C}$-reactive protein (below $5 \mathrm{mg} / \mathrm{L}$, normal range $0-5 \mathrm{mg} / \mathrm{L}$ ). Tumor markers CEA and $\mathrm{Ca} 19-9$ were within normal range.

Due to melena lasting for a week, patient underwent esophagogastroduodenoscopy (EGD) and ultrasound of the abdomen on the outpatient bases only few days prior to admission to the hospital. EGD was technically demanding due to the poor passage of the endoscope 
through the stomach, duodenal bulbous and upper part of the duodenum. Inflation of the gastric body was not possible, therefore the visualization of the gastric wall was poor with no obvious intraluminal mass or hemorrhage detected. Additionally gastric peristalsis was described to be absent. Abdominal ultrasound showed tumor formation of the gastric body, measuring $7 \times 5$ $\mathrm{cm}$, but no intussusception was described. CT scan revealed a $5.4 \times 5.6 \times 6.2 \mathrm{~cm}$ intraluminal tumor formation of the lesser curvature of the gastric body with well defined borders was described. Tumor mass caused invagination of the gastric cardia through the antrum and pylorus into the D2 part of the duodenum producing gastric outlet obstruction (Figs. 1, 2). No dissemination to the parenchymal organs was described.

Explorative laparotomy was performed. Palpable gastric mass with impaction of the tumor through the pylorus into the duodenum without signs of disseminated disease in the abdomen. Was found (Figs. 3, 4). Kocher mobilization of the duodenum and the head of pancreas was necessary for the successful desinvagination of the tumor. Anterior gastrotomy reveled a solid, well defined, intraluminal tumor of the lesser curvature of the gastric body just below the gastroesophageal junction. Circular radical resection of the tumor with one centimeter resection margin was performed. The gastric wall defect was sutured in transverse manner in two layers.

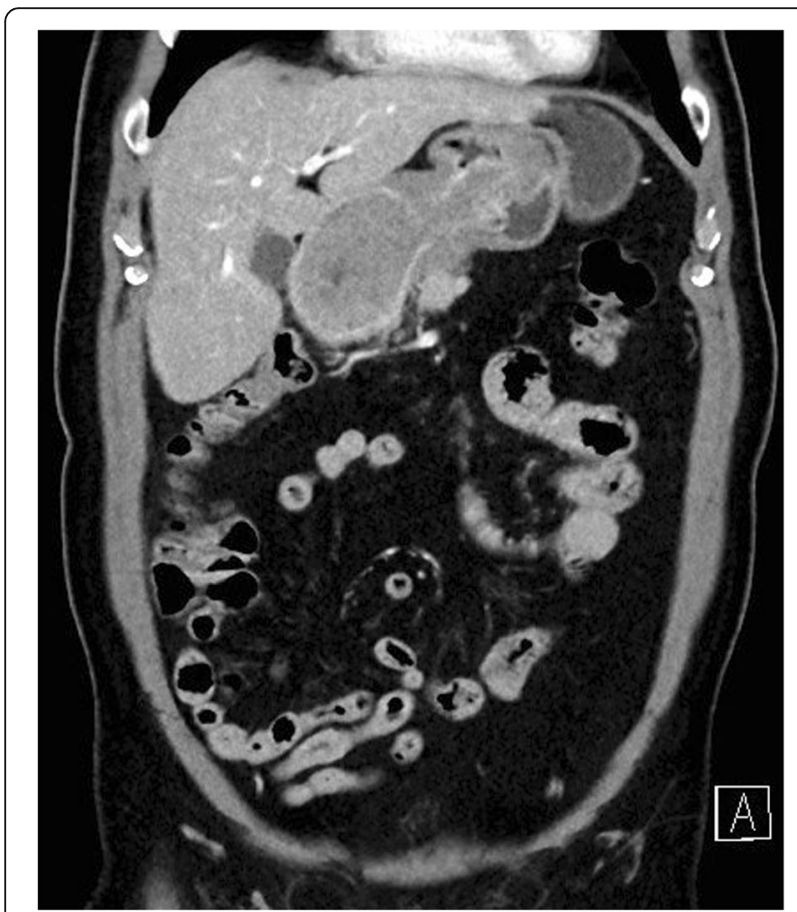

Fig. 1 A CT scan demonstrating an intraluminal tumor of the lesser curvature of the gastric body producing a gastroduodenal intussusception with gastric outlet obstruction

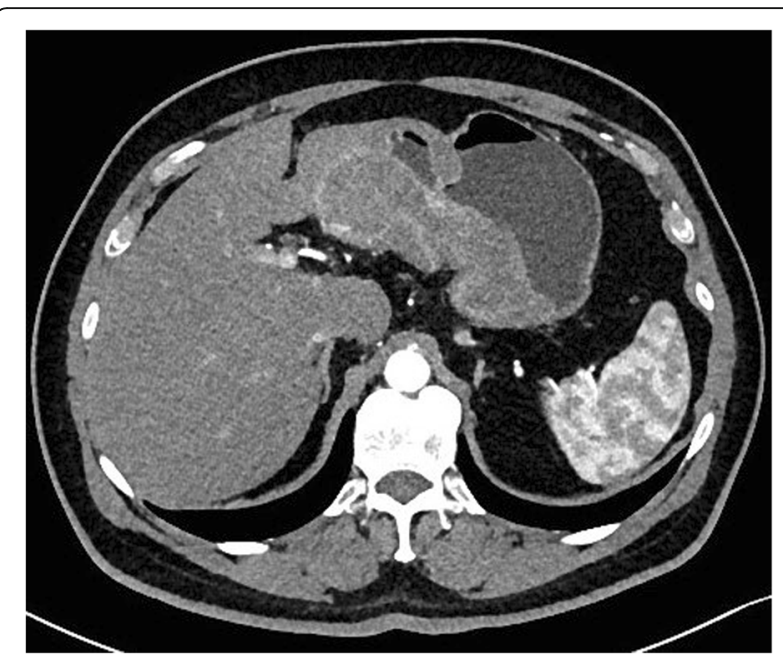

Fig. 2 A CT scan demonstrating an intraluminal tumor of the lesser curvature of the gastric body producing a gastroduodenal intussusception with gastric outlet obstruction

Postoperative period was uneventful and patient was discharged on the ninth postoperative day.

Sample was send for pathohistological examination. Macroscopically specimen contained a well-defined $7.5 \times 5.5 \times 4 \mathrm{~cm}$ solid, grey mass with no necrosis (Fig. 5). Microscopical examination with hematoxylin and eosin staining (HE) and imunohistochemical staining revealed GIST with expression of CD117 and DOG1 (Figs. 6, 7 and 8). Tumor invaded the submucosal layer and muscularis propria but no necrosis or lymphovascular

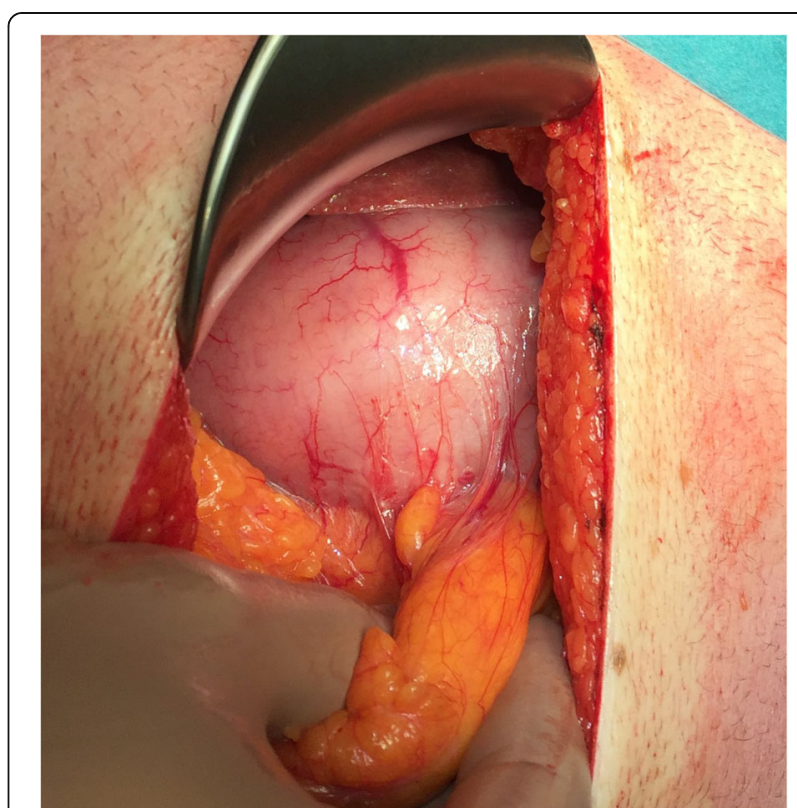

Fig. 3 Palpable intraluminal gastric tumor with the impaction of mass through the pylorus into the duodenum with no other pathological finding in the abdominal cavity 


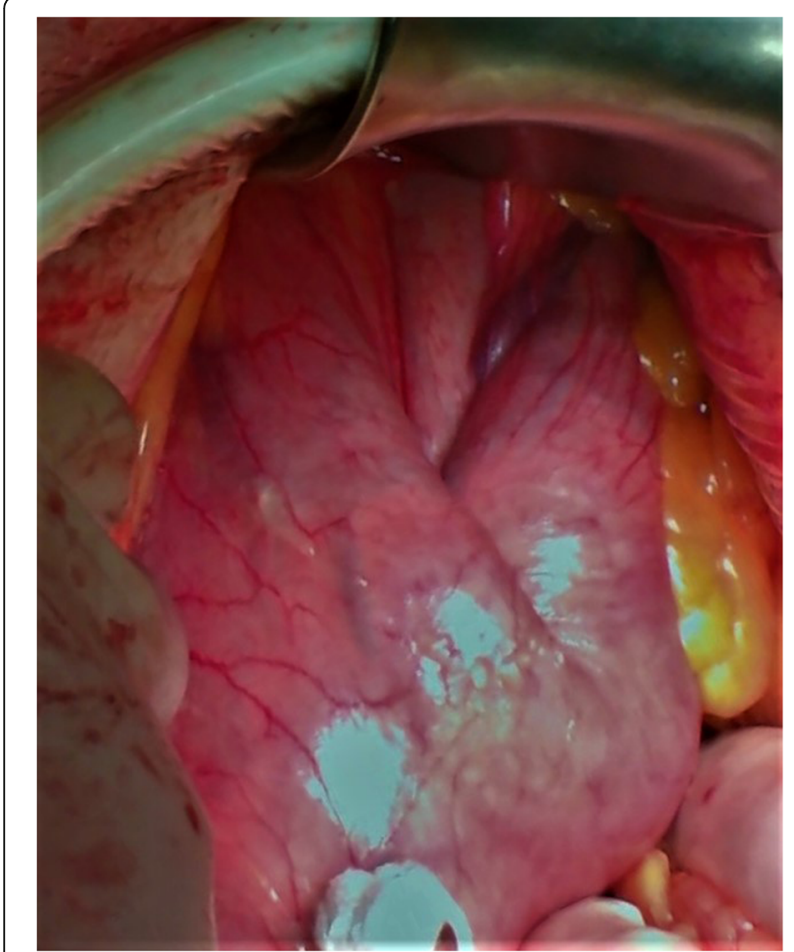

Fig. 4 Palpable intraluminal gastric tumor with the impaction of mass through the pylorus into the duodenum with no other pathological finding in the abdominal cavity

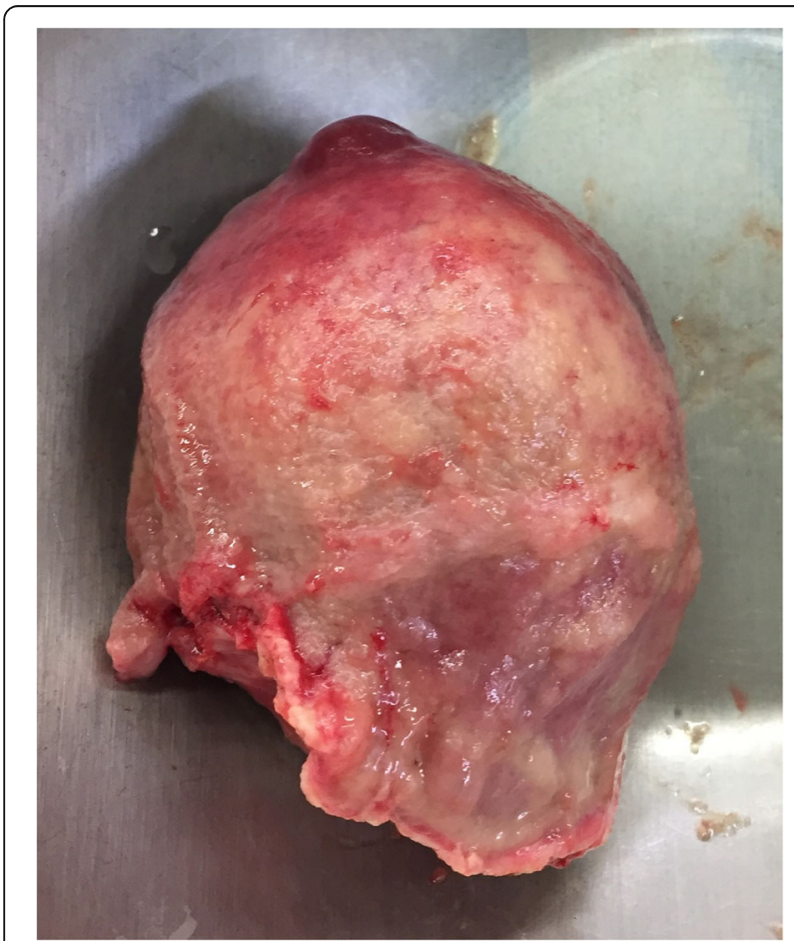

Fig. 5 Solid mass with well defined borders

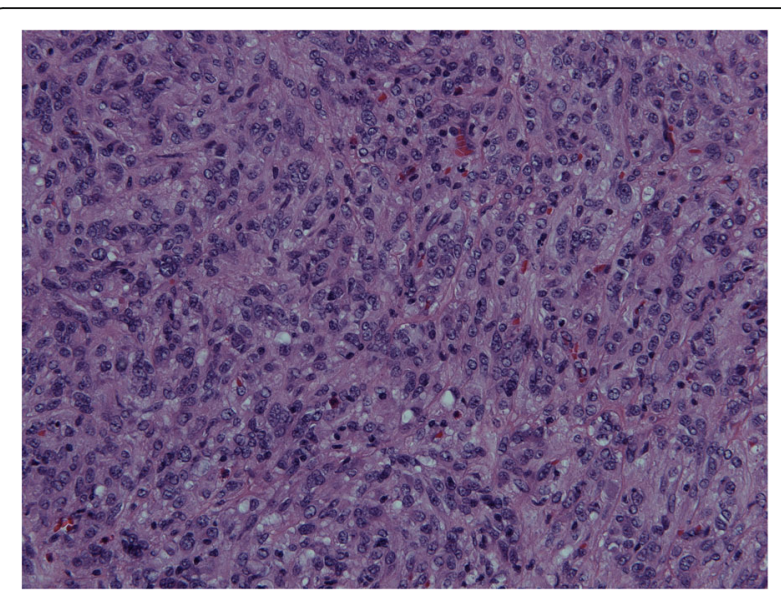

Fig. 6 Microscopic image of GIST, HE staining, $\times 20$ magnification

invasion was observed. Mitotic rate was $0 / 5 / \mathrm{mm}^{2}$. Proliferation marker Ki67 was less than 5\%. Resection margins were free of disease. Tumor was pathologic staged as T3.

Patient case was presented on the multidisciplinary team meeting and due to low-risk GIST with favorable prognosis only observation is suggested.

\section{Discussion and conclusions}

Authors report a case report of 62 years old patient with gastric outlet obstruction due to the gastroduodenal intussusception caused by a large, low risk GIST of the lesser curvature of the gastric body.

Intussusception in adults is an infrequent condition, therefore when the patient presents with the symptoms of the upper gastrointestinal obstruction, other causes should be considered [3]. Gastrointestinal intussusception is a very rare find where malignant or benign lesion of the gastric wall initiates the prolaps of the gastric wall through the pylorous into the duodenum. According to

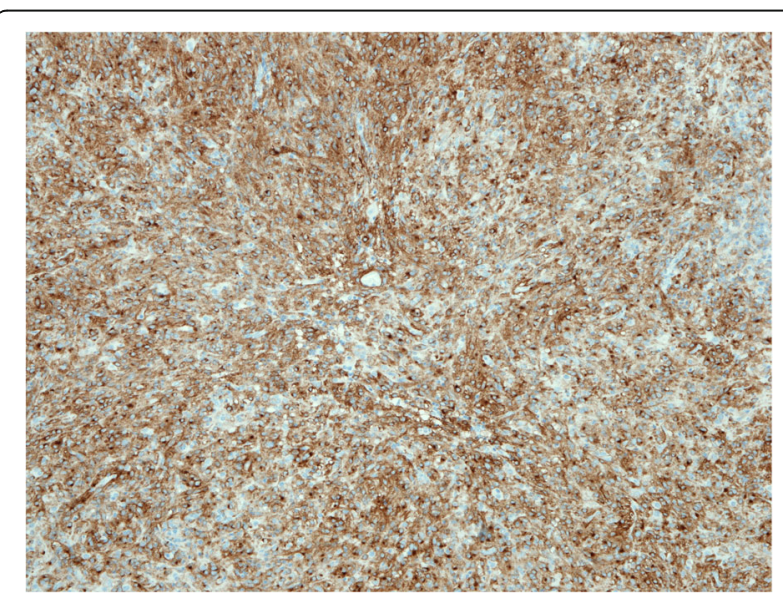

Fig. 7 Microscopic image of GIST, imunohistochemical staining, CD117 positive, $\times 10$ magnification 


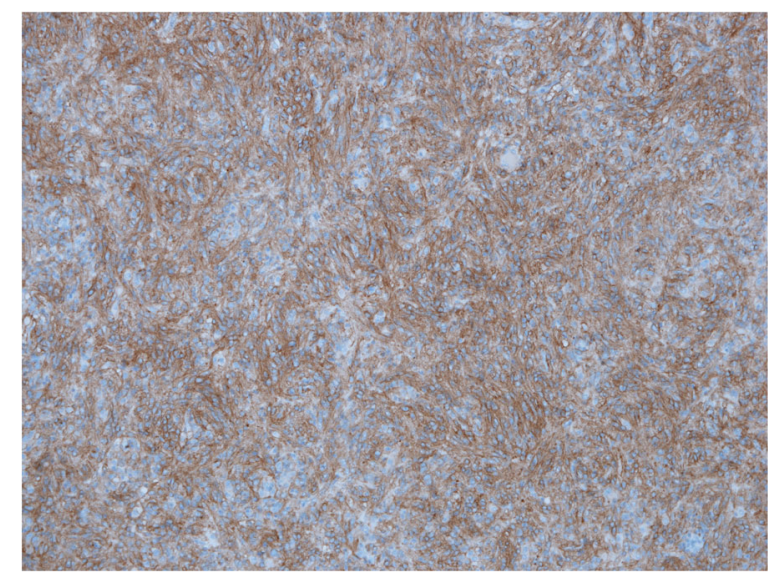

Fig. 8 Microscopic image of GIST, imunohistochemical staining, DOG1 positive, $\times 10$ magnification the literature, gastroduodenal intussusception accounts for only $10 \%$ of documented intussusceptions in the adults [2]. GIST of the gastrointestinal tract are rare, reported incidence is highest in Asia [4]. Most GIST arise from gastric wall (56\%), followed by the small intestine and colon [4]. By authors best knowledge, GIST was described, as a leading point for gastroduodenal intussusception in only 17 cases (Table 1) [5-21].

Reviewing the literature, patients with GIST and gastroduodenal intussusception most commonly presented with nonspecific symptoms of acute or intermittent abdominal pain with vomiting lasting from a day to several months (Table 1) [5-21]. Similar to our patient in some reports GI bleeding was noticed (Table 1) $[9,10,13]$. In the published cases of GIST producing gastroduodenal intussusception reported median age was 65 years (mean 64.5 years, range $29-95$ years), predominantly female (76.5\%) [5-21].

Table 1 Review of the case reports on gastroduodenal intussusception with GIST

\begin{tabular}{|c|c|c|c|c|c|c|}
\hline Reference & $\begin{array}{l}\text { Age } \\
\text { (years) }\end{array}$ & Sex & Location & Size $(\mathrm{cm})$ & Presentation & Treatment \\
\hline Yildiz [5] & 85 & $\mathrm{~F}$ & Fundus & $6 \times 5$ & $\begin{array}{l}\text { Symptoms of acute pancreatitis, weight loss for } 6 \\
\text { months }\end{array}$ & Subtotal gastrectomy \\
\hline $\begin{array}{l}\text { Rittenhouse } \\
{[6]}\end{array}$ & 52 & $\mathrm{~F}$ & Fundus & $5 \times 5$ & Epigastric pain and vomiting for 1 day & Laparoscopic wedge resection \\
\hline Crowther [7] & 59 & $\mathrm{~F}$ & $\begin{array}{l}\text { Anterior wall of } \\
\text { antrum }\end{array}$ & 6 & $\begin{array}{l}\text { Intermittent epigastric pain with vomiting for } 3 \\
\text { weeks }\end{array}$ & Partial gastrectomy \\
\hline M S [8] & 74 & M & Posterior wall & No data & Intermitent vomiting for 3 weeks & Partial gastrectomy \\
\hline Chan [9] & 34 & $\mathrm{~F}$ & $\begin{array}{l}\text { Posterior wall of } \\
\text { fundus }\end{array}$ & $\begin{array}{l}6.5 \times \\
4.4 \times 3.8\end{array}$ & Epigastric pain & Laparoscopic wedge resection \\
\hline Basir [10] & 62 & $\mathrm{~F}$ & $\begin{array}{l}\text { Posterior wall of } \\
\text { distal body }\end{array}$ & $\begin{array}{l}5.2 \times \\
3.5 \times 3.2\end{array}$ & Epigastric pain with melena for 3 days & Bilroth's II partial gastrectomy \\
\hline $\begin{array}{l}\text { Adjepong } \\
{[11]}\end{array}$ & 84 & M & Antrum & $4 \times 3 \times 3$ & $\begin{array}{l}\text { Intermitent abdominal pain, vomiting, weight loss } \\
\text { and melena for } 6 \text { weeks }\end{array}$ & $\begin{array}{l}\text { Laparoscopic bilroth's II partial } \\
\text { gastrectomy }\end{array}$ \\
\hline Wilson [12] & 78 & $\mathrm{~F}$ & Antrum & $\begin{array}{l}4.4 \times \\
3.3 \times 3.4\end{array}$ & Epigastric pain and vomiting for 1 week & Laparoscopic wedge resection \\
\hline $\begin{array}{l}\text { Yamauchi } \\
{[13]}\end{array}$ & 95 & $\mathrm{~F}$ & $\begin{array}{l}\text { Posterior wall of } \\
\text { distal body }\end{array}$ & $4.2 \times 3.9$ & Vomiting, loss of apetite and melena for 1 week & $\begin{array}{l}\text { Endoscopic submucosal } \\
\text { dissection }\end{array}$ \\
\hline Gyedu [14] & 59 & $\mathrm{~F}$ & Anterior wall & $7 \times 6 \times 5$ & Intermitent vomitig for 5 months & Partial gastrectomy \\
\hline Siam [15] & 29 & M & Antrum & $6 \times 6$ & $\begin{array}{l}\text { Intermittent epigastric pain, vomiting and melena for } \\
5 \text { months }\end{array}$ & Bilroth's I partial gastrectomy \\
\hline Zhou [16] & 69 & M & $\begin{array}{l}\text { Posterior wall of } \\
\text { antrum }\end{array}$ & $4.5 \times 4$ & Acute abdominal pain with vomiting for $6 \mathrm{~h}$ & Wedge resection \\
\hline Jameel [17] & 65 & $\mathrm{~F}$ & $\begin{array}{l}\text { Anterior wall of } \\
\text { antrum }\end{array}$ & $6 \times 6 \times 4$ & $\begin{array}{l}\text { Epigastric pain and intermittent postprandial } \\
\text { vomiting for } 6 \text { months }\end{array}$ & Wedge resection \\
\hline Shum [18] & 34 & $\mathrm{~F}$ & Fundus & $5 \times 5$ & Intermittent epigastric pain & Partial gastrectomy \\
\hline $\begin{array}{l}\text { Ssentongo } \\
{[19]}\end{array}$ & 85 & $\mathrm{~F}$ & Fundus & $2.5 \times 2.5$ & $\begin{array}{l}\text { Epigastric pain and melena for } 1 \text { day, postprandial } \\
\text { vomiting for } 14 \text { days }\end{array}$ & Wedge resection \\
\hline $\begin{array}{l}\text { Komatsubara } \\
{[20]}\end{array}$ & 90 & $\mathrm{~F}$ & Fundus & $\begin{array}{l}5 \times 4.5 \times \\
4\end{array}$ & Vomiting, loss of appetite & Wedge resection \\
\hline De $\cup[21]$ & 42 & $\mathrm{~F}$ & $\begin{array}{l}\text { Anterior wall of } \\
\text { antrum }\end{array}$ & $8 \times 7 \times 4$ & Abdominal pain for 6 months & Wedge resection \\
\hline
\end{tabular}


Standard histopathological examination of the specimen and H\&E staining are not enough for the diagnosis of GIST. Immunohistochemical studies are the golden standard [22]. GIST is typically confirmed by positive staining for CD117 antibody as was the case in this report [23]. As proposed in the literature, $4-15 \%$ of GIST can be CD117 negative, therefore additional immunohistochemical staining for DOG1 antibodies should be performed to confirm the diagnosis [24].

In case of gastroduodenal intususception, reduction of the invagination can be performed endoscopically. In described case, where a large GIST led to the intussusception and protrusion of the gastroesophageal junction through the pylorus, endoscopic reduction of the invagination was not feasible. Moreover, upon endoscopy, the stomach was not visible and the tumor was not recognized. Both imaging techniques, ultrasound and CT scan of the abdomen, respectively, described tumor formation of the gastric wall with CT scan describing the gastroduodenal intusussception. Desinvagination and desimpaction of the tumor was not possible until Kocher mobilisation of the duodenum and pancreatic head was performed.

Surgery remains the treatment of choice for resectable GIST with no dissemination but also for oligometastatic disease with potentially resectable liver metastases. In many cases, especially in low-risk GIST, surgery represents the definitive treatment. A wide local resection with clear resection margins is recommended. In cases of invasion to the adjacent organs en-block resection should be performed. Systemic therapy may be indicated in patients with high-risk tumors and in patient with unresectable tumor or metastatic disease. Small lesions can be resected laparoscopically. Endoscopic resection of the GIST is not recommended [25]. In the literature only one case of endoscopic resection of the GIST producing intussusception was described. Endoscopic resection was performed in case of a 95-year-old patient who declined surgery. Tumor mesured $4 \mathrm{~cm}$ and was successfully reduced endoscopically. Due to the repeated invagination and surgery refusal only submucosal dissection of the lesion for the purpose of local treatment was performed [13]. Upon the literature review in cases of GIST producing gastroduodenal intussusception, lesions measured more than $5 \mathrm{~cm}$ (median $5.1 \mathrm{~cm}$, mean $5.3 \mathrm{~cm}$, range $2.5-8 \mathrm{~cm}$ ) [5-21]. As in described case, in majority of patients with large lesions, exploratory laparotomy was performed. The extent of resection ranged from wedge resection to subtotal gastrectomy $[5-8,10,14-$ 21]. In one third of described cases (29.5\%), laparoscopic resection was performed (Table 1 ).

GIST of the gastric wall rarely produces gastroduodenal intussusception. As shown in our case patients with low-grade GIST have favorable prognosis and in most cases radical surgical resection is the only treatment needed. When GIST arise from the gastric wall, resection of the tumor with adequate resection margins should be performed. For small lesions where desinvagination can be achieved endoscopically, laparoscopic resection of the tumor can be considered. In cases of large, impacted lesions, open approach with desinvagination and tumor resection is advisable.

\section{Abbrevations}

EGD: Esophagogastroduodenoscopy; GIST: Gastrointestinal stromal tumor; HE: Hematoxylin and eosin staining

\section{Acknowledgements}

Not applicable.

\section{Authors' contributions}

TB has been involved in the management of the patient and in the conception of the manuscript. JN wrote the manuscript. DM, MP and TB assisted in the preparation of the manuscript and critically reviewed the manuscript. RB contributed to the pathological diagnosis of this patient. SM performed radiologial diagnostics and interpretaded the results. All authors read and approved the final manuscript.

\section{Funding}

None.

Availability of data and materials

All available data are presented in the case.

Ethics approval and consent to participate

Written informed consent was obtained from the patient to participate to this case report.

\section{Consent for publication}

Informed written consent was obtained from the patient for the publication of the clinical details and clinical images.

\section{Competing interests}

The authors declare that they have no competing interests.

\section{Author details}

'Department of Abdominal Surgery, Ljubljana University Medical Center, Zaloška cesta 7, 1000 Ljubljana, Slovenia. ${ }^{2}$ Department of Surgical Oncology, Ljubljana Institute of OncologyActa Chir Belg, Zaloška cesta 2, 1000 Ljubljana, Slovenia. Institute of Pathology, Faculty of Medicine, University of Ljubljana, Korytkova 2, 1000 Ljubljana, Slovenia. ${ }^{4}$ Department of Radiology, Ljubljana University Medical Center, Zaloška cesta 7, 1000 Ljubljana, Slovenia.

Received: 8 May 2019 Accepted: 17 September 2019

Published online: 29 October 2019

\section{References}

1. Azar T, Berger DL. Adult intussusception. Ann Surg. 1997;226:134-8.

2. Stubenbord WT. Intussusception in adults. Ann Surg. 1970.

3. Gambardella C, Allaria A, Siciliano G, Mauriello C, Patrone R, Avenia N, Polistena A, Sanguinetti A, Napolitano S, Conzo G. Recurrent esophageal stricture from previous caustic ingestion treated with 40-year self-dilation: case report and review of literature. BMC Gastroenterol. 2018;18(1):68.

4. Søreide K, Sandvik OM, Søreide JA, Giljaca V, Jureckova A, Bulusu VR. Global epidemiology of gastrointestinalstromal tumours (GIST): a systematic review of population-based cohort studies. Cancer Epidemiol. 2016;40:39-46.

5. Yildiz MS, Doğan A, Koparan IH, Adin ME. Acute pancreatitis and gastroduodenal intussusception induced by an underlying gastric gastrointestinal stromal tumor: a case report. K Gastric Cancer. 2016;16:54-7.

6. Rittenhouse DW, Lim PW, Shirley LA, Chojnacki KA. Gastroduodenal intussusception of a gastrointestinal stromal tumor (GIST): case report and review of the literature. Surg Laparosc Endosc Percutan Tech. 2013;23(2): e70-3. 
7. Crowther KS, Wyld L, Yamani Q, JAcob G. Case report: gastroduodenal intussusception of a gastrointestinal stromal tumour. Br J Radiol. 2002;75: 987-9.

8. M S PB, Reddy CK, Augustine AJ, Sagari SG. Gastroduodenal intussusception due to pedunculated polypoid gastrointestinal stromal tumour (GIST): a rare case. J Clin Diagn Res 2015; 9 (1): PD05-06.

9. Chan CT, Wong SK, Ping Tai Y, Li MK. Endo-laparoscopic reduction and resection of gastroduodenal intussusception of gastrointestinal stromal tumor (GIST): a synchronous endoscopic and laparoscopic treatment. Surg Laparosc Endosc Percutan Tech. 2009;19(3):e100-3.

10. Basir N, Yaakub AB, Kafeel G, Telisinghe PU, Tan KK, Sharif F, Chong VH. Gastroduodenal intussusception as a first manifestation of gastric gastrointestinal stromal tumor. Turk J Gastroenterol. 2012;23(2):185-6.

11. Adjepong SE, Parameswaran R, Perry A, Mathews R, Jones R, Butterworth JR, Sigurdsson A. Gastroduodenal intussusception due to gastrointestinal stromal tumor (GIST) treated by laparoscopic billroth II distal gastrectomy. Surg Laparosc Endosc Percutan Tech. 2006;16(4):245-7.

12. Wilson MH, Ayoub F, McGreal P, Collins C. Gastrointestinal stromal tumour presenting as gastroduodenal intussusception. BMJ Case Rep 2012. bcr2012006787.

13. Yamauchi K, Iwamuro M, Ishii E, Narita M, Hirata N, Okada H. Gastroduodenal intussusception with a gastric gastrointestinal stromal tumor treated by endoscopic submucocal dissection. Intern Med. 2017; 56(12):1515-9.

14. Gyedu A, Reich SB, Hoyte-Williams PE. Gastrointestinal stromal tumour presenting acutely as gastroduodenal intussusception. Acta Chir Belg. 2011; 111(5):327-8.

15. Siam FA, Siow SL. Stomach gastrointestinal stromal tumours (GIST) intussuscepted into duodenum: a case report. Malays J Med Sci. 2008;15(4): 68-70.

16. Zhou Y, Wu XD, Shi Q, Xu CH. Jia J. Gastroduodenal intussusception and pylorus obstruction induced by a c-KIT-negative gastric gastrointestinal stromal tumor: case report and review of the literature.

17. Jameel ARA, Segamalai D, Murugaiyan G, Shanmugasundaram R, Obla NB Gastroduodenal intussusception due to gastrointestinal stromal tumour (GIST). J Clin Diagn Res. 2017;11(8):PD09-10.

18. Shum JS, Lo SS, Ka SY, Yeung CW, Ho JT. Gastroduodenal intussusception. Abdom Imaging. 2007;32(6):698-700.

19. Ssentongo P, Egan M, Arkorful TE, Dorvlo T, Scott O, Oh JS, AmponsahManu F. Adult intussusception due to gastrointestinal stromal tumor: a rare case report, comprehensive literature review, and diagnostic challenges in low-resource countries. Case Rep Surg. 2018;1395230.

20. Komatsubara T, Zuiki T, Lefor AK, Hirota N, Oki J. Unusual gastroduodenal intussusception secondary to a gastrointestinal stromal tumor of the gastric fundus. Int J Surg Open. 2016;5:33-6.

21. De U, Basu S. Gastroduodenal intussusception due to gastrointestinal stromal tumor. Clin Case Rep. 2018;6(11):2276-8.

22. Blay JY, von Mehren M, Blackstein ME. Perspective on updated treatment guidelines for patients with gastrointestinal stromal tumors. Cancer. 2010 Nov 15;116(22):5126-37.

23. Miettinen M, Lasota J. Gastrointestinal stromal tumors: review on morphology, molecular pathology, prognosis, and differential diagnosis. Arch Pathol Lab Med. 2006;130(10):1466-78.

24. Espinosa I, Lee CH, Kim MK, Rouse BT, Subramanian S, Montgomery K, Varma S, Corless CL, Heinrich MC, Smith KS, Wang Z, Rubin B, Nielsen TO, Seitz RS, Ross DT, West RB, Cleary ML, van de Rijn M. A novel monoclonal antibody against DOG1 is a sensitive and specific marker for gastrointestinal stromal tumors. Am J Surg Pathol. 2008:32(2):210-8.

25. Reid R, Bulusu R, Carroll N, Eatock M, Geh I, Judson I, O'Dwyer P, Warren B, Seddon B, Hill G. Guidelines for the Management of Gastrointestinal Stromal Tumours (GIST). Association of Upper Gastrointestinal Surgeons of Great Britain and Ireland, 2009.

\section{Publisher's Note}

Springer Nature remains neutral with regard to jurisdictional claims in published maps and institutional affiliations.

\section{Ready to submit your research? Choose BMC and benefit from:}

- fast, convenient online submission

- thorough peer review by experienced researchers in your field

- rapid publication on acceptance

- support for research data, including large and complex data types

- gold Open Access which fosters wider collaboration and increased citations

- maximum visibility for your research: over $100 \mathrm{M}$ website views per year

At BMC, research is always in progress.

Learn more biomedcentral.com/submissions 